\title{
Prediction of Severe Thunderstorms applying Neural Network using RSRW Data
}

\author{
Himadri Chakrabarty \\ Associate Professor, Dept. of Computer \\ Science, Surendranath College, Calcutta \\ University, Visiting Fellow, Institute of \\ Radiophysics and Electronics, Calcutta Univ. \\ Kolkata, India
}

\author{
Sonia Bhattacharya \\ Contractual Whole Time Teacher in Dept. of \\ Computer Science, \\ Panihati Mahavidyalaya \\ Barasat State University \\ Kolkata, India
}

\begin{abstract}
Severe thunderstorm is a seasonal and mesoscale atmospheric event. The sudden increase in wind speed and the other weather features during this event have various destructive effects on the people. Correct forecasting with enough lead time is very important to minimize the damages occurring in day-to-day life. In this paper, artificial neural network technique has been applied to predict the severe thunderstorm. Multilayer Perceptron (MLP) has been applied on the weather parameters of moisture difference, adiabatic lapse rate and vertical wind shear which were recorded by the radiosonderawind (RSRW) in the early morning at 06.00 am local time. MLP classified and predicted 'severe storm' and 'no storm' days in this work correctly nearly up to $70 \%$ having around 12 hours lead time.
\end{abstract}

\section{General Terms}

Pattern Recognition, Squall, Mesoscale.

\section{Keywords}

Artificial Neural Network, Multilayer Perceptron, RSRW, Severe Thunderstorm and Wind-shear.

\section{INTRODUCTION}

Severe local thunderstorm is the extreme weather convective phenomenon. It is accompanied with very strong surface wind, lightning, thunder, smart shower, and sometimes with hailstones. The strong surface wind is known as squall, which is a sudden and sharp increase in the wind speed of 45 kilometers or more per hour during a short time interval of minimum 1 minute, [1]. Such type of thunderstorm is generated by the small-scale convection of cumulonimbus cloud. In small-scale convection, air is accelerated upward under the buoyancy provided by the release of latent heat during condensation on the cloud particles, [2]. The intensities of convection depend not alone upon the degree of atmospheric instability, but the manner by which the instability is created and released, and the particular character of the circulation in the resulting storm, [3]. There occur severe thunder-squalls and hailstorms in India, including Nor'westers of North-East India, Bangladesh and Assam in the pre-monsoon period, [4]. The jet stream in the upper troposphere $(500-\mathrm{mb})$ flows over these regions as strong westerlies [4]. Ludlam in 1963 showed the distribution of areas in the subtropical regions of the world where severe squall-storms occur. There is an equator-ward advancing cold fronts which are probably closely associated with the storm outbreaks, [2]. The favorable condition for storm generation is the distribution of potential temperature for deep convection, the field of vertical motion (or low level convergence), and a 'triggering mechanism', [2]. Storms are forecast to occur where there is a combination of favorable circumstances, and their severity can be assessed by the application of parcel theory, [2]. Superposition of upper-level divergence over lower-level convergence is the favorable process for convective storm generation, [3].

Severe squall-storms can cause destructions of various dimensions, like uprooting of trees, electric polls, electrocuttings, damages of weak structures and crops, blockage of roads and railway traffic, [5]. The effects of Nor'wester have tremendous impacts just after the occurrence of the event. The remedial measures must be taken when meteorological departments issue the forecast of these events. Correct forecast having enough lead-time is very important factor to save the people from the catastrophy caused by such natural disaster. Thunderstorm forecasting is a challenging job due to the dynamic nature of the atmosphere, [6]. To predict severe thunderstorms, different weather variables from surface level to the various heights of the upper air are necessary. The atmospheric data are observed during the whole day at different time intervals. In the present work, the weather data which are considered are moisture difference, dry adiabatic lapse rate and vertical wind shear at different geo-potential levels of the atmosphere. Moisture difference and adiabatic lapse rate are the measure of instability of the atmosphere, [7]. Wind shear is an important parameter to measure the potential of severity and duration of squall line. In this paper our main aim is to observe how much correct forecast can be done using these three upper air parameters with 10 to 12 hours lead time. The upper air data were collected at the location of Kolkata $\left(22.3^{\circ} \mathrm{N} / 88.3^{\circ} \mathrm{E}\right)$, situated in North-East India during the period of 18 years from 1990 to 2008 for the months of March-April-May (MAM). These three months are known as pre-monsoon months in North-East India. The upper air weather variables which have been considered for analysis here were observed by radiosonde and rawindsonde (RSRW) in the morning time at around 06.00 local time (00.00UTC).

The neural network of appropriate complexity is trained to recognize the underlying directional pattern of the storm, without formulating complex equations which are quite often restrained by the model limitations [8]. The main features of ANN are its ability to map input data to output data to any degree of non-linearity [9]. Neural Network is a generalization of traditional statistical methods for non-linear regression and classification [10]. The objective is to develop a learning algorithm for a multilayer feed-forward neural 
network, so that it can be trained to capture the mapping implicit in the given set of input-output pattern pairs [11]. Multi layer perceptron (MLP) and K-nn techniques have been applied by Chakrabarty2 et al., 2013 to predict squall-storms occurring in Kolkata using only two types of weather variables such as adiabatic lapse rate and moisture difference from surface level to five different geopotential heights of the atmosphere with around 12 hours lead time, resulting $91 \%$ accuracy in forecast. Neural network classifiers have been attractive alternatives to conventional classifiers by numerous researchers, [12] and it is also studied in the fields of speech and image recognition. Here in this work, neural networkMulti-Layer-Perceptron (MLP) has been applied on the weather variables for the prediction of 'squall-storm' or 'no squall-storm' days.

\section{DATA \\ 2.1 Data Collection}

All the weather data were collected from India Meteorological Department, Govt. of India during the period of 18 years (1990-2008) for the months of March-April-May. The data considered for analysis here are both for the days when squallstorms occurred and for some of the days when squall-storms did not occur. The numbers of 'squall-storm' days are 69 and 'no squall-storm' days are 270. The whole data-points have been divided into six sets, taking one set as testing set and remaining sets as training set. In each set squall and no-squall data has been arranged in 1:4 orders. Each set has been considered as test set and the remaining as training set for six different datasets.

\subsection{Data Description}

Three atmospheric parameters have been considered here for the analysis. These are moisture difference, dry adiabatic lapse rate and vertical wind shear. We have discussed about these three variables in the following sub-sections.

\subsubsection{Moisture Difference}

The moisture difference has been considered at (i) surface level $\left(x_{1}\right)$, and then at different geo-potential heights of the upper air, such as at (ii) $1000 \mathrm{hpa}\left(x_{2}\right)$, (iii) $850 \mathrm{hpa}\left(x_{3}\right)$, (iv) $\left.700 \mathrm{hpa} \mathrm{(} x_{4}\right)$, and (v) $600 \mathrm{hpa}\left(x_{5}\right)$ which are measured at approximately 75 meters, 1500 meters, 3100 meters, and 4500 meters respectively from mean sea level (MSL). Moisture difference (MD=T-Td) is the difference between dry bulb temperature $(\mathrm{T})$ and dew point temperature $(\mathrm{Td})$ of the atmosphere. This moisture difference profile indicates the measurement of humidity from the surface to the upper atmosphere of 4.5 kilometers height, from MSL, signifying the amount of saturation in the atmosphere in the morning on the 'squall-storm' days as well as on the 'no storm' days.

\subsubsection{Adiabatic Lapse Rate:}

Dry adiabatic lapse rates at different geo-potential heights are determined by dry bulb temperature difference between consecutive two levels (d T / d Z), which are considered as five input parameters (predictors), such as (i) surface and 850 hpa (approximately surface to 1500 meters), denoted by $x_{6}$, (ii) $850 \mathrm{hpa}$ and $700 \mathrm{hpa}$ (approximately 1500 to 3100 meters), denoted by $x_{7}$, (iii) $700 \mathrm{hpa}$ and $600 \mathrm{hpa}$ (approximately 3100 to 4500 meters), denoted by $x_{8}$, (iv) $600 \mathrm{hpa}$ and $400 \mathrm{hpa}$ (approximately 4500 to 7500 meters), denoted by $x_{9}$, and (v) 400 hpa and 300 hpa (approximately 7500 to 9600 meters), denoted by $x_{10}$, [6]. The more the conditional instability remains in the atmosphere, more moisture would be carried out to the upper atmosphere from the surface level to form thunderclouds, [13]. The conditional instability can be evaluated by the dry adiabatic lapse rate of the atmosphere, [7].

\subsubsection{Wind-shear:}

The wind shear at four different geopotential heights of the atmosphere are considered as three input variables (predictors), represented by $x_{11}, x_{12}$, and $x_{13}$. The wind shear has been calculated by the difference in wind speed between two consecutive heights of the upper air with respect to the difference between those respective heights (dw/dx). The altitudes in the upper air at which wind shears have been calculated are (i) $900 \mathrm{hpa}$ and $700 \mathrm{hpa}$ (approximately 980 meters to 2500 meters, say $\mathrm{x}_{11}$ ), (ii) $700 \mathrm{hpa}$ and $500 \mathrm{hpa}$ (approximately 2500 meters to 12340 meters, say $\mathrm{x}_{12}$ ) and (iii) $500 \mathrm{hpa}$ and $200 \mathrm{hpa}$ (approximately 12340 meters to 35000 meters, say $\mathrm{x}_{13}$ ). In low to medium shear environments, mature thunderstorms will contribute modest amount of downdrafts, enough to turn will aid in creating a leading edge lifting mechanism - the gust front. In high shear environments created by

opposing low level jet winds and synoptic winds, updrafts and consequent downdrafts can be much more intense (common in super cell mesocyclones). Linear theory predicts that an initially axisymmetric updraft interacts with a shear flow in a way that produces a favorable vertical pressure gradient, [14] to produce severe thunderstorms.

\section{METHODOLOGY}

Artificial Neural Network (ANN) has been applied here for correct prediction of 'squall-storm' and 'no squall-storm' days. Multilayer Perceptron (MLP) technique has been adopted in this work.

\section{Multilayer Perceptron (MLP)}

A three layered MLP network has been designed here. There is one hidden layer along with an input layer and an output layer (Figure 1). The input layer consists of thirteen input nodes which are weather variables. These thirteen variables are moisture differences, adiabatic lapse rates and vertical wind-shears. First five input data represent moisture differences at different heights of the upper air denoted by $\mathrm{x}_{1}$, $\mathrm{x}_{2}, \mathrm{x}_{3}, \mathrm{x}_{4}$ and $\mathrm{x}_{5}$. Input variables $\mathrm{x}_{6}, \mathrm{x}_{7}, \mathrm{x}_{8}, \mathrm{x}_{9}$ and $\mathrm{x}_{10}$ represent adiabatic lapse rates at several geo-potential levels of the atmosphere. The remaining three input variables i.e., $\mathrm{x}_{11}, \mathrm{x}_{12}$ and $x_{13}$ represent vertical wind-shears at various geo-potential heights. Fourteenth variable is considered as a 'bias' term having value ' 1 '. The number of hidden nodes considered in the hidden layer varies from 8 to 14. Each 3-layered MLP network has been run to get the outputs. The output layer consists of two nodes $\mathrm{Y}_{1 \mathrm{k}}$ and $\mathrm{Y}_{2 \mathrm{k}}$, which denote 'squall storm' and 'no squall storm' events respectively. 


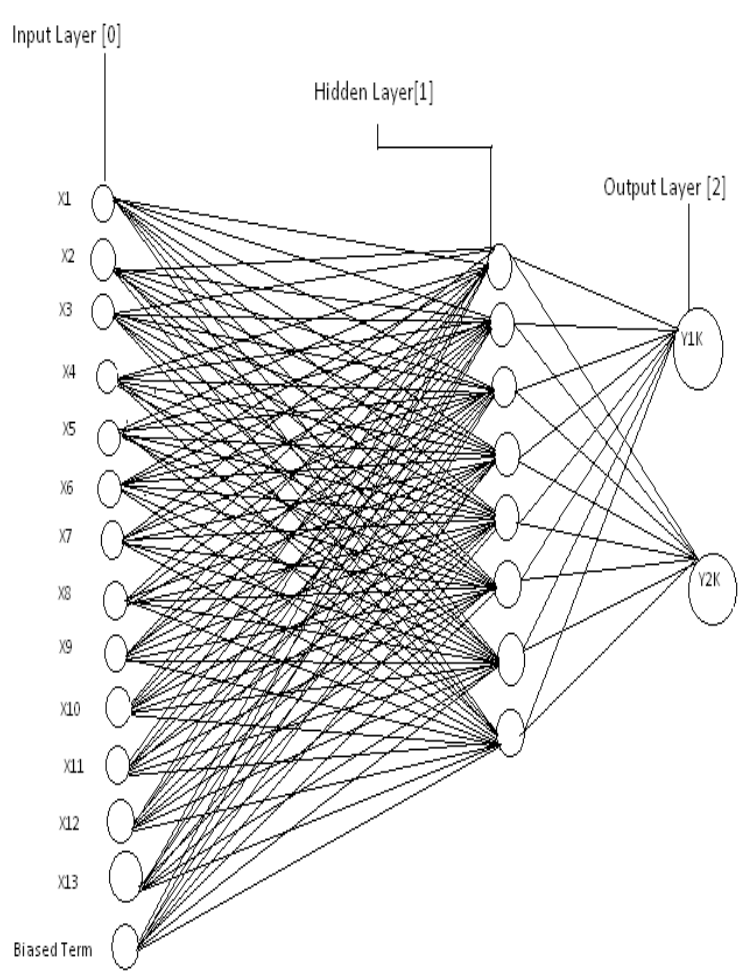

Fig 1: A three layered 14-8-2 MLP network

\subsection{Learning Phase}

In the learning phase of the Multilayer Perceptron, the value 1,0 for nodes $Y_{1 \mathrm{k}}$ and $Y_{2 \mathrm{k}}$ respectively in the output layer would mean that the input is a 'squall storm' data point and 0 , 1 for nodes $Y_{1 k}$ and $Y_{2 k}$ respectively would mean the observation corresponds to 'no storm' day. Each unit of each layer is connected to each unit of the next layer by the connection weights. A sigmoid function, which is a nonlinear activation function, is widely used as a transfer function. There are two ways of learning the weights of an MLP: Batch mode learning and On-line learning. Here, Batch-mode method of learning the weights is followed.

\subsection{Feed-forward Stage}

In this stage each node (say $i$ ) in a layer is joined to each node (say $j$ ) in the next layer by a connection weight represented by $W_{i j}$. The weight values are chosen in the range from -0.5 to 0.5 . Let $x_{i}$ be the i-th input node in the

input layer. Let a node in the hidden layer is $y_{j}$. Then the total input received for the $\mathrm{j}$-th node in the hidden layer is $Y_{j}=$ $\sum_{i=1}^{n} X_{i} W_{i j}$

The output from the $\mathrm{j}$-th node of the hidden layer is $Y_{j}$. A transfer function is used to obtain this. This is a nonlinear activation function.

$Y_{j}=\frac{1}{1+\exp \left(\left[-Y_{j}\right)\right.}$

This is valid for every layer.

\subsection{Error}

The error function is the mean square error, which is expressed by,

$$
E=\frac{\sum_{j=1}^{2}\left(e_{j}-o_{j}\right)^{2}}{2}
$$

The expected output $(e)$ for every point in the training set is known. For a particular observation, the actual (calculated) output value for the $\mathrm{j}$-th node in the output layer is $o$. This error is to be minimized during the training phase by the back propagation. Iteration is continued until the error is minimized around 0.005 to 0.001 .

\subsection{Back Propagation Phase}

The performance of the back propagation learning law depends on the initial setting of the weights, learning rate parameter, output function of the units, presentation of the training data. Modification of the weights using back propagation is done by learning the given set of training patterns in the iterative manner several times. Learning rate parameter $\eta$ plays a crucial role in the back propagation learning. In this paper, the value of $\eta$ is assumed as 0.01 . The back propagation basically uses gradient descent technique to minimize the error and to change the weights. The objective is to determine the weights update for each presentation of an input-output pattern pair. Since given data may be used several times during training, let us use the index $m$ to indicate the presentation step for the training pair at step $m$. For training a multilayer feed-forward neural network, we use the following estimate of the gradient descent along the error surface to determine the increment in the weight connecting the units $j$ and $i$.

$\Delta W_{i j}(m)=-\eta \frac{\partial E(m)}{\partial W_{i j}}$

\subsection{Modification of weights}

The weight update is given by,

$W_{i j}(m+1)=W_{i j}(m)+\Delta W_{i j}(m)$

The modified weights are used in test dataset for the validation of the outputs. In some cases, large number of iteration or unsatisfactory test set produces large error value. In such cases, the architecture of MLP is to be changed by changing the number of nodes in the hidden layer. So several 3 layered MLPs are to be studied. The different 3-layered architectures of MLPs which were used in this study are 14-8$2,14-9-2,14-10-2,14-11-2,14-12-2$ 14-13-2, and 14-14-2 with different combinations of training and testing data sets. 


\section{RESULT}

Results using 3 layered MLP in batch mode process is shown in table 1 and table 2 .

Table 1. Results of three layered MLP using different models

\begin{tabular}{|c|c|c|c|}
\hline $\begin{array}{l}\text { Design } \\
\text { of the } \\
\text { network }\end{array}$ & $\begin{array}{l}\text { No. of } \\
\text { correctly } \\
\text { classified } \\
\text { and \% of } \\
\text { accurate } \\
\text { points for } \\
\text { 'squall } \\
\text { storm' } \\
\text { days in } \\
\text { test data } \\
\text { set }\end{array}$ & $\begin{array}{l}\text { Number of } \\
\text { correctly } \\
\text { classified } \\
\text { and \% of } \\
\text { accurate } \\
\text { points for } \\
\text { 'no squall- } \\
\text { storm' } \\
\text { days in the } \\
\text { test } \\
\text { dataset. }\end{array}$ & $\begin{array}{l}\text { Total number } \\
\text { of correctly } \\
\text { classified and } \\
\% \text { of accurate } \\
\text { points in the } \\
\text { test dataset. } \\
\text { Datasets of both } \\
\text { 'squall-storm' } \\
\text { and 'no squall- } \\
\text { storm' days } \\
\text { considered. }\end{array}$ \\
\hline SET I & $\begin{array}{l}\text { Total no. } \\
\text { of squall } \\
\text { days }=17\end{array}$ & $\begin{array}{l}\text { Total no. } \\
\text { of } \\
\text { squall days } \\
=27\end{array}$ & $\begin{array}{l}\text { Total no. of days } \\
=44\end{array}$ \\
\hline $14-8-2$ & $3,17.64 \%$ & $26,96.29 \%$ & $29,65.90 \%$ \\
\hline $14-9-2$ & $3,17.64 \%$ & $26,96.29 \%$ & $29,65.90 \%$ \\
\hline $14-10-2$ & $4,23.52 \%$ & $24,88.88 \%$ & $28,63.63 \%$ \\
\hline $14-11-2$ & $2,11.76 \%$ & $25,92.59 \%$ & $1.36 \%$ \\
\hline $14-12-2$ & $3,17.64 \%$ & $25,92.59 \%$ & $28,63.63 \%$ \\
\hline 14-13-2 & $4,23.52 \%$ & $25,92.59 \%$ & $29,65.90 \%$ \\
\hline $14-14-2$ & $4,23.52 \%$ & $25,92.59 \%$ & $29,65.90 \%$ \\
\hline SET II & $\begin{array}{l}\text { Total no. } \\
\text { of squall } \\
\text { days }=17\end{array}$ & $\begin{array}{l}\text { Total no. } \\
\text { of } \\
\text { squall days } \\
=28\end{array}$ & $\begin{array}{l}\text { Total no. of days } \\
=45\end{array}$ \\
\hline $14-8-2$ & $5,29.41 \%$ & $27,96.42 \%$ & $32,71.11 \%$ \\
\hline $14-9-2$ & $1,5.88 \%$ & $27,96.42 \%$ & $28,62.22 \%$ \\
\hline $14-10-2$ & $9,52.94 \%$ & $22,78.57 \%$ & $31,68.88 \%$ \\
\hline & $5,29.41 \%$ & $26,92.85 \%$ & $31,68.88 \%$ \\
\hline $14-12-2$ & $2,11.76 \%$ & $27,96.42 \%$ & $29,64.44 \%$ \\
\hline 14-13-2 & $2,11.76 \%$ & $25,89.28 \%$ & $27,60 \%$ \\
\hline $14-14-2$ & $3,17.64 \%$ & $27,96.42 \%$ & $30,66.66 \%$ \\
\hline
\end{tabular}

Table 2. Results of three layered MLP using different models

\begin{tabular}{|c|c|c|c|}
\hline $\begin{array}{l}\text { Design } \\
\text { of the } \\
\text { network }\end{array}$ & $\begin{array}{l}\text { No. of } \\
\text { correctly } \\
\text { classified } \\
\text { and \% of } \\
\text { accurate } \\
\text { points for } \\
\text { 'squall } \\
\text { storm' } \\
\text { days in } \\
\text { test data } \\
\text { set }\end{array}$ & $\begin{array}{l}\text { Number of } \\
\text { correctly } \\
\text { classified } \\
\text { and \% of } \\
\text { accurate } \\
\text { points for } \\
\text { 'no squall- } \\
\text { storm' days } \\
\text { in the test } \\
\text { dataset. }\end{array}$ & $\begin{array}{l}\text { Total number } \\
\text { of correctly } \\
\text { classified and } \\
\% \text { of accurate } \\
\text { points in the } \\
\text { test dataset. } \\
\text { Datasets of both } \\
\text { 'squall-storm' } \\
\text { and 'no squall- } \\
\text { storm' days } \\
\text { considered. }\end{array}$ \\
\hline SET III & $\begin{array}{l}\text { Total no. } \\
\text { of squall } \\
\text { days }=17\end{array}$ & $\begin{array}{l}\text { Total no. of } \\
\text { no squall } \\
\text { days }=27\end{array}$ & $\begin{array}{l}\text { Total no. of days } \\
=44\end{array}$ \\
\hline $14-8-2$ & $5,31.25 \%$ & $25,89.28 \%$ & $30,68.18 \%$ \\
\hline $14-9-2$ & $9,56.25 \%$ & $24,85.71 \%$ & $33,75 \%$ \\
\hline $14-10-2$ & $2,12.5 \%$ & $27,96.42 \%$ & $29,65.90 \%$ \\
\hline $14-11-2$ & $3,18.75$ & $25,89.28 \%$ & $28,63.63 \%$ \\
\hline $14-12-2$ & $6,37.5 \%$ & $23,82.14 \%$ & $29,65.90 \%$ \\
\hline $14-13-2$ & $4,25 \%$ & $26,92.85 \%$ & $30,68.18 \%$ \\
\hline $14-14-2$ & $4,25 \%$ & $26,96.42 \%$ & $31,70.45 \%$ \\
\hline SET IV & $\begin{array}{l}\text { Total no. } \\
\text { of squall } \\
\text { days }=16\end{array}$ & $\begin{array}{l}\text { Total no. of } \\
\text { no squall } \\
\text { days }=28\end{array}$ & $\begin{array}{l}\text { Total no. of days } \\
=44\end{array}$ \\
\hline $14-8-2$ & $6,35.29 \%$ & $25,89.28 \%$ & $31,68.88 \%$ \\
\hline $14-9-2$ & $2,11.76 \%$ & $25,89.28 \%$ & $27,60 \%$ \\
\hline $14-10-2$ & $6,35.29 \%$ & $25,89.28 \%$ & $25,55.55 \%$ \\
\hline $14-11-2$ & $4,23.52 \%$ & $22,78.57 \%$ & $26,57.77 \%$ \\
\hline $14-12-2$ & $4,23.52 \%$ & $25,89.28 \%$ & $29,64.44 \%$ \\
\hline $14-13-2$ & $3,17.64 \%$ & $23,82.14 \%$ & $29,64.44 \%$ \\
\hline $14-14-2$ & $4,23.52 \%$ & $25,89.28 \%$ & $29,64.44 \%$ \\
\hline SET V & $\begin{array}{l}\text { Total no. } \\
\text { of squall } \\
\text { days }=16\end{array}$ & $\begin{array}{l}\text { Total no. of } \\
\text { no squall } \\
\text { days }=28\end{array}$ & $\begin{array}{l}\text { Total no. of days } \\
=44\end{array}$ \\
\hline $14-8-2$ & $5,31.25 \%$ & $26,92.85 \%$ & $31,68.88 \%$ \\
\hline $14-9-2$ & $1,6.25 \%$ & $28,100 \%$ & $27,60 \%$ \\
\hline 14-10-2 & $6,35.29 \%$ & $25,89.28 \%$ & $31,68.88 \%$ \\
\hline $14-11-2$ & $3,17.64 \%$ & $23,82.14 \%$ & $26,59.09 \%$ \\
\hline $14-12-2$ & $4,23.52 \%$ & $25,89.28 \%$ & $29,65.90 \%$ \\
\hline $14-13-2$ & $3,17.64 \%$ & $25,89.28 \%$ & $28,63.63 \%$ \\
\hline $14-14-2$ & $4,23.52 \%$ & $26,92.85 \%$ & $30,68.18 \%$ \\
\hline SET VI & $\begin{array}{l}\text { Total no. } \\
\text { of squall } \\
\text { days }=16\end{array}$ & $\begin{array}{l}\text { Total no. of } \\
\text { no squall } \\
\text { days }=28\end{array}$ & $\begin{array}{l}\text { Total no. of days } \\
=44\end{array}$ \\
\hline $14-8-2$ & $7,43.75 \%$ & $26,92.85 \%$ & $33,75 \%$ \\
\hline $14-9-2$ & $3,17.64 \%$ & $27,96.42 \%$ & $30,68.18 \%$ \\
\hline $14-10-2$ & $2,12.5 \%$ & $28,100 \%$ & $30,68.18 \%$ \\
\hline $14-11-2$ & $4,23.52 \%$ & $26,92.85 \%$ & $30,68.18 \%$ \\
\hline $14-12-2$ & $3,17.64 \%$ & $25,89.28 \%$ & $28,63.63 \%$ \\
\hline $14-13-2$ & $3,17.64 \%$ & $27,96.42 \%$ & $30,68.18 \%$ \\
\hline 14-14-2 & $3,17.64 \%$ & $26,92.85 \%$ & $29,65.90 \%$ \\
\hline
\end{tabular}




\section{Table 3. Misclassification rates of different MLP models}

\begin{tabular}{|l|l|l|l|}
\hline $\begin{array}{l}\text { Design } \\
\text { of the } \\
\text { network }\end{array}$ & $\begin{array}{l}\text { Miss- } \\
\text { classification } \\
\text { rate of } \\
\text { 'squall class' }\end{array}$ & $\begin{array}{l}\text { Miss- } \\
\text { classification } \\
\text { rate of 'no- } \\
\text { squall class' }\end{array}$ & $\begin{array}{l}\text { Total Miss- } \\
\text { classification } \\
\text { rate }\end{array}$ \\
\hline $14-8-2$ & 0.7 & 0.02 & 0.29 \\
\hline $14-9-2$ & 0.8 & 0.05 & 0.38 \\
\hline $14-10-2$ & 0.7 & 0.09 & 0.34 \\
\hline $14-11-2$ & 0.78 & 0.11 & 0.35 \\
\hline $14-12-2$ & 0.77 & 0.09 & 0.34 \\
\hline $14-13-2$ & 0.8 & 0.09 & 0.34 \\
\hline $14-14-2$ & 0.77 & 0.06 & 0.32 \\
\hline
\end{tabular}

It is observed from Table- 1 and Table- 2 that 14-8-2 model of MLP on an average yields the most satisfactory result comparing with the other 6 models of MLP. Total number of data accurately classified by 14-8-2 MLP classifier is nearly $70 \%$, and misclassification rate is 0.29 (Table-3). Chakrabarty1 et al. (2013) predicted squall-storm using wind shear parameter from rawind data. Chakrabarty2 et al. (2013) also now casted severe thunderstorm by the weather parameters of moisture difference and adiabatic lapse rate from radiosonde data. In both the cases, artificial neural network- MLP has been used.

\section{CONCLUSION}

Generally, radiosonde-rawind (RSRW) data are required to predict thunderstorm event in a conventional way. In this paper, artificial neural network (ANN) has been applied to determine the two separate classes "squall-storm' and 'no storm'. Here, ANN-MLP classified approximately $70 \%$ of the whole data of 'squall-storm' days and 'no storm' days in a correct manner. Different types of 3-layered MLP architectures were used. Here, the best MLP classifier is revealed as $14-8-2$. The misclassification rate is minimum with respect to the other MLP structures used here.

\section{ACKNOWLEDGEMENT}

The authors are thankful to India Meteorological Department, Govt. of India for providing atmospheric data to do this research work.

\section{REFERENCES}

[1] Chakrabarty 1, Himadri, C. A. Murthy, Sonia Bhattacharya and Ashis Das Gupta, May, 2013. "Application of Artificial Neural Network to Predict Squall-Thunderstorms Using RAWIND Data", International Journal of Scientific \& Engineering Research, Volume 4, Issue 5, pp. 1313-1318, ISSN 2229-5518.

[2] Ludlam, F.H., Sept., 1963. "Severe Local Storms", Meteorological Monographs, American Meteorological Society, Volume 5, Number 27, pp. $1-30$.
[3] Newton, C.W., Sept., 1963. "Dynamics of Severe Convective Storms", Meteorological Monographs, American Meteorological Society, Volume 5, Number 27, pp. 33-58.

[4] Ramaswami, C., 1956. "On the sub-tropical jet stream and its role in the development of large-scale convection", Tellus, 8, 26-60.

[5] Chakrabarty, Himadri, 2010. "Synoptic Aspects of Nor'wester and its Impact to the People in Kolkata, North-East India", International Journal of Science in Society, Vol. 1, Issue 4, pp.135-148.

[6] Chakrabarty 2, Himadri, C.A.Murthy, and Ashish Das Gupta, 2013. "Application of Pattern Recognition Techniques to Predict Severe Thunderstorms", International Journal of Computer Theory and Engineering, Vol. 5, No. 6, pp. 850-855

[7] Moran, J.M., M.D.Morgan, and P.M.Pauley, 1997. "Meteorology: The Atmosphere and the Science of Weather", $5^{\text {th }}$ Edition, Prentice Hall.

[8] Jigme Singye, Katsumi Masugata, Tadakuni Murai, Iwao Kitamura and Honda Kontani, 2006. "Thunder Storm Tracking System using Neural Networks and Measures Electric Field from a few Field Mills", Journal of Electrical Engineering, vol 57 No. 2, 87-92.

[9] Sharma Sanjay, Devajyoti Dutta, J. Das, and R.M.Gariola, 2009. "Nowcasting of severe storms at a station by using the Soft Computing Techniques to the Radar Imagery", 5 th European Conference on Severe Storms, Landshut-Germany, 2009.

[10] Marzban Caren, June, 2003. "Neural Networks for Postprocessing Model Output: ARPS", Monthly Weather Review, Volume 131, 1103-1111, June, 2003.

[11] Yegnanarayana B, 1999, Artificial Neural Networks, Prentice Hall of India Pvt Ltd.

[12] Chung, C.Y.C. and V.R. Kumar, 1993. "Knowledge acquisition using a neural network for weather forecasting knowledge-based system," Neural Computing \& Applications, Springer, London, Volume 1, Number 3, pages.215-223.

[13] Volland, H., 1995. Handbook of Atmospheric Electrodynamics, Vol. 1.

[14] Richard Rotunno and Joseph B. Klemp, 1982. "The Influence of the Shear-Induced Pressure Gradient on Thunderstorm Motion", Monthly Weather Review, Volume 110, pp. 136-151. 